\title{
Approaches in the Photosynthetic Production of Sustainable Fuels by Cyanobacteria using Tools of Synthetic Biology
}

\author{
Indrajeet . ${ }^{1}$, Akhil Rautela ${ }^{1}$, and Sanjay Kumar ${ }^{1}$ \\ ${ }^{1} \mathrm{IIT}$ BHU
}

July 24,2021

\begin{abstract}
Cyanobacteria, photosynthetic prokaryotic microorganisms having a simple genetic composition are the prospective photoautotrophic cell factories for the production of a wide range of biofuel molecules. Simple genetic composition of cyanobacteria allows effortless genetic manipulation which leads to increased research endeavour from the synthetic biology approach. An improved development of synthetic biology tools, genetic modification methods and advancement in transformation techniques to construct a strain which can contain multiple target genes in single operon will vastly expand the functions that can be used for engineering photosynthetic cyanobacteria for the generation of biofuels. In this review, recent advancements and approaches in synthetic biology tools and biofuel production by metabolically engineered cyanobacteria have been discussed. Various fuel molecules like isoprene, limonene, $\alpha$-farnesene, squalene, alkanes, butanol and fatty acids which can be a substitute of petroleum and fossil fuels in future have been elaborated.
\end{abstract}

\section{Introduction}

Industrialization and the human population explosion have created a huge energy crisis worldwide due to their dependence on the non-conventional fossil fuels like petroleum, coal and natural gases to fulfil their daily energy requirements (Chandrasekhar et al., 2015; Kumar et al., 2017; Pandey et al., 2020). Extensive use of fossil fuels also generates a huge amount of harmful greenhouse gases which get accumulated in the environment and adversely affect the life on the planet. Harvesting solar energy via photosynthesis is one of nature's noteworthy achievements that could also be a solution for the future world-wide energy need. Cyanobacteria which can fix $\mathrm{CO}_{2}$ into organic compounds using solar energy are of great significant cellular factories for producing biofuels (Knoll et al., 2008; Testa et al., 2019). In addition to sunlight as an energy source for carbon absorption, cyanobacteria require water and inorganic trace nutrients for growth. Among the photosynthetic organisms, cyanobacteria offer attractive systems for biotechnological applications due to their higher growth rate compared to plants and they are relatively acquiescent to genetic manipulation compared to microalgae which opens ample opportunities to modify complex biosynthetic pathways by synthetic biology approaches (Lu et al., 2010; Lin et al., 2021). Synthetic biology deals with this and aims to manipulate the existing genetic system and create the new one with greater capabilities. To fulfil these objectives, variety of genetic tools have been developed such as engineered promoters (constitutive and inducible), ribosome binding sites library (RBS), riboswitches, CRISPR/Cas system, vectors, etc (Li et al., 2016; Sengupta et al., 2020). These tools come under the common term "BioBricks" which stands for the part of the DNA. Some strains of cyanobacteria can accumulate large amounts of lipids and are excellent candidates for biodiesel production (Quintana et al., 2011; Eungrasamee et al., 2020). The concept of converting carbon dioxide into a desirable fuel gave rise to genetically engineered cyanobacteria for biofuel production (Atsumi et al., 2009: Lindberg et al., 2010; Knoot et al., 2018). The first model cyanobacterium 
was Synechocystis sp. PCC 6803 for which the complete genome was sequenced in 1996 (Kaneko et al., 1996). Some cyanobacterial model strains, Synechocystis sp. PCC 6803, Synechococcus elongatus sp. PCC 7942, Synechococcussp. PCC 7002, , Synechococcus elongatus UTEX 2973, Synechococcus elongatus PCC 11801 and Synechococcus elongatus PCC 11802 have been used in synthetic biology and metabolic engineering studies for biosynthesis of multiple fuel molecules including free fatty acids, isoprene, 2,3-butanediol, 1-butanol, squalene, n-alkanes, $\alpha$ - farnesene and hydrogen etc. Some attributes of cyanobacteria like high cell density growth, ability to grow on non-arable land, utilization of different water sources (fresh, marine and waste water) and capability to produce both biofuels and other economically important products qualifies them a suitable cell factory (Zahra et al., 2020).

\section{Recent Toolboxes for Synthetic Biology in Cyanobacteria}

Due to limitations in the molecular biology tools available for cyanobacteria in comparison to the other bacteria ( $E$. coli ), there is a need to design these tools using a synthetic biology approach. Synthetic biology manipulates the already available tools native or foreign and recombining them using different combinations for a better output. In this view, several tools like promoters, riboswitches, ribosome binding sites, CRISPR/Cas system, etc. were developed, which are briefly reviewed here. Strains likeSynechococcus elongatus PCC 7942, Synechocystis sp. PCC 6803, etc. are used as a host to test these genetic tools. One of the major demerits of these strains is the longer doubling time. Recently Yu et al. (2015) discovered Synechococcus elongatus UTEX 2973, which is the fastest-growing strain reported to date. Table 1 summarizes the commonly used cyanobacterial strains as hosts. $<$ Table $1>$

\subsection{Promoters}

There are number of native and foreign promoters that are used in cyanobacteria and are summarized in Table 2. In bacteria, promoters are recognised by the $\sigma$ factor of the RNA polymerase (RNA P) enzyme and aids in the transcription of the gene of interest. The promoters can be constitutive or inducible. Constitutive promoters transcribe the genes continually in an unregulated way. Whereas inducible promoters are specific to the signals like light, dark, heavy metals, nitrate/nitrite, etc. and are helpful when the intermediate/end products are toxic to the host cells. $\mathrm{P}_{\mathrm{cpc} 560}$ considered as the super-strong promoter, was discovered by Zhou et al. (2014). It has the same expression rate as that of the E. coli producing functional proteins at a level of up to $15 \%$ of total soluble proteins. It has two promoters from the cpcB gene and 14 transcription factor binding sites, which are assumed to be the crucial factor for its strength. In one of the studies done by Liu and Pakrasi (2018), promoter cpcB showed the highest expression (sequence identical to cpc560). They compared 13 different promoters by checking the expression of enhanced yellow fluorescence protein. Out of the thirteen promoters, twelve were native, and one was E. coli originated. Wang et al. (2018) constructed promoters' library, compared 17 different promoters, and concluded that $\mathrm{P}_{\operatorname{trc}}$ gives two times better expression than the promoter $\mathrm{P}_{\mathrm{psbA}}$ (from chloroplast of the flowering plantAmaranthus hybridus ) and seven times expression than $\mathrm{P}_{\mathrm{cpcB}}$ (Pcpc560) and its variants. The expression level was checked by expressing the ethylene forming enzyme inSynechocystis sp. PCC 6803. $\mathrm{P}_{\operatorname{trc} 2 \mathrm{O}}$ and $\mathrm{P}_{\operatorname{trc1O}}$ (Huang et al., 2010 and Camsund et al., 2014) is the promoter derived from $\mathrm{P}_{\text {trc }}$ (Brosius et al., 1985). $\mathrm{P}_{\text {trc1O }}$ has a strong lac operator than $\mathrm{P}_{\operatorname{trc}}$, whereas $\mathrm{P}_{\text {trc2O }}$ has two lac operator site showing efficient repression. Markley et al. (2014) constructed a promoter which performs better than trc promoter, giving $48 \pm 7$ fold expression of YFP. They constructed two orthogonal promoter libraries with the IPTG induction system, which were tried and tested in Synechococcus sp. strain PCC 7002. Promoter MB1, MB2, and MB3 were obtained by a change in sequences in the Biobrick promoter J23119. Similarly, 20 different synthetic promoters were assembled by modifying J23119, $\mathrm{P}_{\text {trc10 }}, \mathrm{P}_{\text {tic10 }}$, and $\mathrm{P}_{\text {tac10 }}$ promoters, and the intensity of fluorescence was checked in Synechocystis and Synechococcus elongatus UTEX 2973 (Vasudevan et al., 2019). In both the cases, J23119 showed the highest fluorescence levels. Werner et al. (2018) discovered and characterized nineteen native promoters in Synechocystis sp. PCC 6803, which are induced by 12:12 hour light and dark cycles (LD 
cycles). Out of these nineteen promoters, four of the promoters $\mathrm{P}_{\text {hlic }}, \mathrm{P}_{\mathrm{rbp} 1}, \mathrm{P}_{\text {slr00061, }}$, and $\mathrm{P}_{\text {sigA }}$ shows a strong correlation with 12:12 LD cycles when characterized using bacterial luciferase bioluminescent gene. In the same species, metal ions (nickel, cobalt, and zinc) induced nrsB, nrsD, nrsS, coaT, and ziaA promoters were compared with endogenous constitutive promoters (Englund et al., 2016). $\mathrm{P}_{\mathrm{nrsB}}$ was found to be the most efficient promoter, which can be regulated and tuned with the help of nickel ion. Kelly et al. (2018) inserted a rhamnose-inducible rhaBAD promoter from E. coli toSynechocystis sp. PCC 6803 which showed a controlled expression system. $\mathrm{P}_{\text {synDIF }}$, a short 48 nucleotides long synthetic promoter for heterocyst-specific expression in filamentous cyanobacteria (Wegelius et al., 2018) can be used well for the production of oxygen intolerant enzymes as the promoter gives 10 times more expression after the heterocyst formation. Expression of the promoter changes when it is relocated from the native location to the new one (Albers and Peebles 2016). $\mathrm{P}_{\mathrm{psbAII}}$ within the native genomic location of Synechocystis sp. PCC 6803 showed 15.8 times increase in the transcript in comparison to only 1.6 times when the promoter is moved to neutral region slr0168. Promoter psbA was used to control the expression of mannitol encoding genes ( $m t l D$ and $m l p$ ) inSynechococcus sp. PCC 7002, giving a yield of $1.1 \mathrm{~g}$ mannitol L ${ }^{-1}$ with a production rate of $0.15 \mathrm{~g}$ mannitol L $\mathrm{L}^{-1}$ day $^{-1}$ (Jacobsen and Frigaard, 2014). Huang and Lindblad (2013) constructed non-inducible promoters and showed that altering a few base pairs can change the strength of the promoters. R40 promoter was used as a template for promoter designing. Specific base pairs changes were done in the R40 promoter at TATAAT site (L12 promoter created whose strength is less than R40) and between -10 element and transcription start site (L12 promoter having strength more than R40). Three line of modifications were done between -10 element and transcription start site creating a total of 19 promoters, L01 to L016, L21 and L22, and L31. The study shows that L21 promoter has 110 (+-1) times strength than L22, opening the possibilities to change the region between -27 and +3 at TATAAT sequence. Bioinformatics tools play an important role in the prediction of promoters in cyanobacteria. Btss finder is one of the means for bacterial promoter prediction, which includes E. coli and cyanobacteria. Being novel, it can identify the promoters of different sigma classes of two different phyla. Various native and foreign promoters are shown in table 2.

$<$ Table $2>$

\subsection{Ribosome Binding Sites}

As the promoters regulate the initiation of transcription, in the same way, ribosome binding sites (RBS) regulate translation initiation rate of downstream target genes (Kierzek et al., 2001). Upon translation initiation, with the help of complementary base pairing of the nucleotides, the 3-terminal sequence of the 16S rRNA interacts with the core Shine-Dalgarno (SD) sequence of RBS. Ma et al. (2002) showed this in Synechocystis 6803 that the 3 terminal sequence of the $16 \mathrm{~S}$ rRNA is AUCACCUCCUUU and its complementary SD sequence is AAAGGAGGUGAU (core SD sequence underlined). To enhance the production of 2,3-butanediol in Synechococcus 7942, expression levels of the three genes (alsS, alsD and adh) are coordinated by utilizing four different RBS from E. coli (Oliver et al., 2014). Wang et al. 2016 increased limonene synthesis by RBS engineering in Synechococcus elongatus PCC 7942. Strain L1113 showed limonene production of 32.8 $\mu \mathrm{g} / \mathrm{L} / \mathrm{OD} / \mathrm{d}$ by changing the original RBS of the trc promoter. Similarly, a synthetic RBS introduced in psbA promoter increased the limonene production to $885.1 \mu \mathrm{g} / \mathrm{L} / \mathrm{OD} / \mathrm{d}$. RBS library for cyanobacteria was created by Englund et al. (2016) by utilizing 8 RBS sequences from BioBrick Registry of standard biological parts and two from Synechocystis sp. PCC 6803 and predicted by "RBS library calculator". The mentioned library was used to express an enhanced yellow fluorescent protein (eYFP) with the help of PnrsB, PnrsD, PnrsS, PcoaT and PziaA promoters which are induced by nickel, cobalt and zinc metal efflux pumps. More recently, Liu et al. (2018) evaluated 20 native RBS, which were 22 base pair long. Ptrc1O was selected as the promoter to check the strength of the RBS sequences by the EYFP gene. In the same manner, Thiel et al. (2018) also assessed 13 RBS out of which 7 were native ofSynechocystis 6803, and 6 were from $E$. coli . Codon-optimized GFPmut3, sYFP2, and ethylene forming enzyme were used as the reporter proteins for checking translation efficiency. These studies help in the selection of suitable RBSs for overexpression of the end product. According to Reeve et al. (2014), the same RBS can have inconstant translational efficiencies in different microorganisms or different genes in the same organisms. RBS calculating tools plays 
an important role which is based on the thermodynamic model to predict the changes in the start codon and 5 untranslated regions in an mRNA transcript. RBS calculator, UTS design and RBS designer are the majorly used tools to determine translation rates. Each calculator is used efficiently for reverse and forward engineering. RBS calculator prognosticates TIR by enumerating the strength of $30 \mathrm{~S}$ complex and mRNA transcript interaction (Salis et al., 2009 and Salis et al., 2011). RBS designer (Na and Lee, 2010) works by designing RBS sites synthetically on the RNA transcript, while the UTR designer (Seo et al., 2013) focuses on changing 5-UTR to alter protein expression and predicts translation efficiency. These tools serve an importance purpose of generating RBS libraries, but efficiency of them can vary. Wang et al. (2017) reported the low efficiency of RBS library created by RBS calculator and established a rational RBS design strategy. Likewise, Thiel et al. (2018) also stated that the data predicted by UTR designer and RBS calculator shows different translation efficiency than the experimental one. In another study numerous RBS calculated for bisabolene synthase gene gives $7.8 \mathrm{mg} / \mathrm{L}$ titer (Sebesta and Peebles, 2020).

\subsection{Riboswitches}

In comparison with the inducible promoters, riboswitches do not require additional protein factors (RNA P) and are cis-acting regulatory element which changes the conformation on binding with its ligand controlling TIR (Henkin 2008; Domin et al., 2017). This makes riboswitches an ideal tool for gene regulation. Nakahira et al. (2013) illustrated that modified theophylline-responsive riboswitches regulate gene (luciferase) expression more efficiently than inducible promoters. Further, this riboswitch was used in many studies in Synechococcus elongatusPCC 7942, Leptolyngbya sp . strain BL0902, Anabaena sp . strain PCC 7120, and Synechocystis sp. Strain WHSyn andSynechocystis 6803 to check the expression regulation of yellow and green fluorescent protein (Ma et al., 2014; Ohbayashi et al., 2016). The theophylline-responsive riboswitches used were earlier screened and characterized in the past in Gram-negative alpha- and gamma-proteobacteria and Gram-positive bacteria (Lynch and Gallivan, 2009; Topp et al., 2010). It is also used to regulate intracellular glycogen content (40 to $300 \%$ of wild type) in Synechococcus elongatus PCC7942 by controlling ADP-glucose pyrophosphorylase (GlgC). Optimised level of glycogen increases cellular robustness (Chi et al., 2019). Apart from theophylline-responsive riboswitches, cobalamin-dependent riboswitch work well in Synechococcus 7002 as the strain cannot synthesize the cobalamin itself (Perez et al., 2016). But this riboswitch cannot work in the strain which synthesize cobalamin such as Synechococcus 7942, Synechocystis 6803, Crocosphaerawatsonii WH8501 and Synechococcus sp. WH7803 (Helliwell et al., 2016). Other riboswitches used in cyanobacteria includes S-box (SAM), SAM-II (a-proteobacteria) and SAMI/IV-variant riboswitch, thiamine pyrophosphate (TPP)-riboswitch, Glycine riboswitch, SMK box translational riboswitch, Purine riboswitch, FMN riboswitch (RFN element), Lysine riboswitch, SAH ( $S$-adenosyl-l-homocysteine) riboswitch, THF (Tetrahydrofolate) riboswitch Moco (molybdenum cofactor) riboswitch, (Sun et al., 2013; Zhang and Gladyshev, 2008; Singh et al., 2018). Some of the riboswitches inducer are toxic to the host organism and are key metabolic intermediates, therefore, only theophylline dependent riboswitch is widely used in cyanobacterial systems.

\subsection{CRISPR Based Technique}

The most recent synthetic biology tool is the CRISPR/Cas system, which is marker less. CRISPR/Cas stands for Clustered regularly interspaced short palindromic repeats/ CRISPR associated proteins. Its targetability is provided by the single-guide RNA (sgRNA), which is specific to the target genomic site. SgRNA directs the Cas protein to the target site which cleaves both the strand of the genome. Cyanobacteria being oligoploid and polyploid in nature shows difficulty in producing homozygous mutants (Watanabe et al., 2015 and Zerulla et al., 2016). CRISPR based technique improve this editing efficiency. Wendt et al (2016) used CRISPR/Cas 9 system to produce nonbleaching protein A (nblA) mutants of Synechococcus elongatus UTEX 2973. Once all the copies of the genes are deleted the mutants show visible results (within 1 week) as the nblA serves as visual reporter gene. These results were verified by Li et al (2016) by increasing the succinate concentration inSynechococcus elongatus PCC 7942 through glgc knock-out glta/ppc 
(citrate synthase/phosphoenol pyruvate carboxylase) knock in by CRISPR-Cas 9 editing. Cas 9 at higher concentrations showed toxicity inS. elongatus UTEX 2973 and PCC 7942 cells (Wendt et al., 2016 and Li et al., 2016). The quick fix to the problem was the transient expression of Cas 9 through temperature-controlled plasmid. This gave inkling to Ungerer \& Pakrasi (2016) to prospect CRISPR/Cas 12a (also known as Cpf1). Markerless point mutation, a knock-out mutation or a knock-in mutation were generated $S$. elongatus UTEX 2973,Synechocystis sp. PCC 6803 and Anabaena sp. PCC 7120. Cas 12 have several merits over Cas 9 which includes, no requirement of tracrRNA to activate crRNA, cost efficient as it needs only 42 nucleotides RNA which is cheaper to produce, and PAM (Protospacer adjacent motif) sequence is more specific to the cleavage site. A recent application of Cas 12a was seen in developing high-throughput prototyping tool for promoter characteristics (Choi et al., 2021). This gives opportunity to rapidly characterize promoters by cell free transcription. A newer version of CRISPR/Cas system is CRISPR-interference (CRISPRi) which utilizes the dead Cas9 (dCas9) which binds to the target DNA but has lost the ability to cleave it. This type of system is essential for the genes which are crucial for the cell viability and can only be downregulated rather deleted. Yao et al. (2016) first reposted the application of CRISPRi in Synechocystis sp . PCC 6803. The sgRNAs were placed in the neutral sites (slr2030-slr2031) due to this $94 \%$ of repression was seen in the GFP protein. CRISPRi can be used for producing carbon-based products as shown by Huang et al. (2016). They effectively repressed extrinsic (EYFP) and intrinsic genes (glgc, sdhA and sdhB) to redirect the carbon flow. This laid the foundation for the metabolic pathways in cyanobacteria. Similarly, CRISPRi is being also used to redirect fatty acid flux (Kaczmarzyk et al., 2018). Regulating plsx (phosphate acyltransferase) gene by CRISPRi system fatty alcohol production enhanced to a great extent at $10.3 \mathrm{mg} / \mathrm{g}$ dry weight. Modulation of glutamine sythetase (glnA helps in nitrogen assimilation) in Anabaena sp . PCC 7120 was shown by Higo et al. (2018). The process is regulated in such a way that ammonium is produced only when dCas inducer is present in the system. Lately, dCas12a-mediated CRISPR interference system (CRISPRi-dCas12a) was developed in cyanobacteria for repressing genes which are not needed to produce value added chemicals (repression upto 53-94\%). The technique was implemented in PCC 7942 to increase squalene production by repressing aconitase (Choi and Woo, 2020).

\subsection{Vectors}

After successfully finalizing the genetic elements like promoters, RBS, riboswitches, etc. a platform is required for taking the gene of interest into the host cell (here, cyanobacteria). For this purpose, vectors come into role, which is a plasmid with properties having antibiotic resistance gene for selection, mobilization elements for transfer and unique restriction sites for cloning. The heterologous gene can be inserted into the genome of the cyanobacteria or replicate autonomously. The former is done with the help of integrative and latter with replicative vectors. Replicative vectors are easy to use to insert gene of interest in cyanobacteria for the bioproduction and other purposes (Heidorn et al., 2011). Autonomous expression of gene without getting inserted in the genome gives higher expression (Xia et al., 2019). Shuttle vectors, commonly used are replicative plasmids as they can express in two hosts. Jin et al. (2018) constructed shuttle vector for PCC 6803 utilizing its own plasmid. PCC 6803's plasmid PCC 5.2 consists a replicon and combining it with pMB1 (origin of replication of $E$. coli ) leads to the formation of shuttle vector pSCB-YFP. Replicative vectors require antibiotic selection/stress to stably maintain them. Table 3 shows the list of replicative vectors available for research purposes. There are number of neutral sites detected in the genome of cyanobacteria like NS I, NS II, etc. (Ng et al., 2015). Replacing these neutral sites with the gene of interest with the help of homologous recombination is the widely used method as shown in figure 1 (Lee et al., 2017). Another strategy includes integrating the heterologous gene in place of the genes which do have function in cyanobacteria or does not affect the robustness of the strain. In this case the heterologous gene utilizes the promoter, RBS, and terminator sequences of the source gene. High ploidy level in cyanobacteria prove to be the major drawback in integration of gene of interest as it is to be ensured that each and every copy has the gene (Heidorn et al., 2011). This is epitomized by Griese et al. (2011) stating PCC 7942 having 3 to 4 genomic copies per cell, and PCC 6803 having 218 and 58 genomic copies in exponential and stationary phase respectively. Earlier there was no modular cloning (MoClo) (Engler et al., 2014) system for cyanobacteria, however Vasudevan et al. 
(2019) combined plant MoClo with cyanobacteria making CyanoGate system kit. The kit consists of 96 parts and these can be combined with each other from level 0 to level $\mathrm{T}$ to form replicative or integrative vectors. All vectors are submitted at addgene for research purposes (Addgene Kit \#1000000146). Commercially available replicative plasmids are listed in table 3 and integrative plasmids have been listed in table 4 .

$<$ Figure $1><$ Table $3><$ Table $4>$

\section{Transformation Techniques}

Ease in the genetic modification process has been a very essential necessity for a cyanobacterial strain development using synthetic biology tools for metabolic engineering applications. Currently, three procedures are being widely used for the insertion of target gene into cyanobacterial host cells: transformation, conjugation and electroporation (Vioque, 2007). The efficiency of transformation in cyanobacteria depends on biochemical and physical barriers which varies from species to species (Stucken et al., 2013). Transformation also depends on the size, structural organization and concentration of the target DNA used in engineering process (Nagarajan et al., 2011). Transformation can be done by using either integrative plasmid or by replicative plasmid. DNA transfer by integrative plasmid employs the foreign DNA incorporation into the genomic DNA of host cells by the process called homologous recombination (Heidorn et al., 2011). Whereas, replicative plasmids replicate and express independently along with foreign DNA in the host cell (Wang et al., 2013). These two types of plasmids have been well developed for the transformation of cyanobacteria. It has already been demonstrated the possibility of using linear DNA segment in Synechocystis sp. for metabolic engineering applications (Nagarajan et al., 2011). Synechococcus elongatusPCC 7942 was first time engineered with linear DNA fragment using EDTA as DNases inhibitor (Daneilla et al., 2017). Some cyanobacterial strains like Synechocystis 6803 (Lindberg et al., 2010),Synechococcus PCC 7942 (Johnsberg et al., 2007) andSynechococcus PCC 7002 (Xu et al., 2011) are naturally competent to take foreign DNA. This attribute of natural competency is not common in other strains. Target DNA can be transferred in noncompetent strains by a well-developed method called tri-parental conjugation, which employs helper, conjugal and replicable plasmids (Yu et al., 2015). DNA transmission from E. coli to nitrogen fixing cyanobacterial strains of Nostoc and Anabaena have been genetically manipulated (Ruffing, 2011). In a study Yu et al. (2015) has successfully applied tri-parental conjugation process inSynechococcus UTEX 2973 with the help of helper and conjugal plasmids because they are not naturally transformable, like its close relative Synechococcus PCC 6301. Table 5 summarizes the different DNA transfer strategies used for cyanobacterial genetic manipulation.

$<$ Table $5>$

\section{Prominent fuel molecules produced by modified cyanobacteria}

In recent years, cyanobacteria has been a suitable candidate for metabolic engineering for the production of potential fuels to overcome concerns related to energy crises and greenhouse gas emission and could be a great alternative of sustainable and renewable energy (Melis, 2009 and Woo, 2017). Cyanobacteria harvest solar energy through photosynthesis and synthesize simple sugars and a variety of metabolite intermediates which functions as precursors of biofuels (Knoot et al., 2018). Till now many fuel molecules have been efficiently produced by metabolically engineered cyanobacteria in good yields which are shown in Table 6 . Schematic biosynthetic pathway of various molecules having fuel properties are demonstrated in figure 2 .

< Table $6>$

$<$ Figure $2>$ 


\subsection{Isoprene}

Isoprene (2-methyl-1,3-butadiene), a volatile hydrocarbon molecule which is naturally synthesized in the leaves of deciduous and perennial plants like oak, kudzu and eucalyptus and emitted in the environment at higher temperature (Melis, 2012; Chaves, 2018). Naturally microorganisms like algae bacteria and cyanobacteria do not synthesize isoprene. However isoprene synthase gene from the higher plants can be isolated and transferred in microbes for microbial production of isoprene. Nowadays cyanobacteria have attracted researcher's attention for their capabilities of fast growth rate and simple genetic composition which qualifies them as great photosynthetic chassis for biofuel production. Cyanobacteria don't possess isoprene synthase gene which catalyses the conversion of di-methylallyl diphosphate (DMAPP) to isoprene, the final step of isoprene synthesis. However they are equipped with methyl erythritol phosphate (MEP) pathway (figure 2) for the synthesis of a variety of terpenoid molecules (Lichtenthaler, 2000). The first step of MEP isoprenoid biosynthetic pathway is catalysed by deoxy xylulose synthase (DXS) enzyme which utilises glyceraldehyde 3 phosphate (G3P) and pyruvate as initial substrate and converts into deoxy-xylulose phosphate (DXP). Which is further converted to di-methylallyl diphosphate (DMAPP) and isopentenyl diphosphate (IPP) through a series of enzyme catalysed reactions. Cyanobacteria also have been reported to contain an IPP isomerase that catalyses the inter-conversion of IPP and DMAPP (Barkley et al., 2004). Heterologous expression of isoprene synthase gene from plant has been the strategy of many researchers to produce isoprene in cyanobacterial system. First cyanobacterial production of isoprene was reported by Lindberg et al. (2010). They introduced plant's (Pueraria montana) isoprene synthase gene (IspS) into Synechocystis PCC 6803 under the light regulated PsbA2 promoter. The yield of isoprene was $50 \mu^{-1} g^{-1} \mathrm{DCW}$. Another research group used intermittent addition of $\mathrm{CO}_{2}$ using isoprene synthase (IspS) gene engineeredSynechocystis sp . PCC

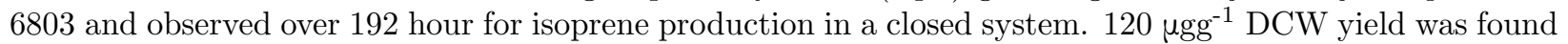
(Bentley et al., 2012). When, isoprene synthase gene is expressed in combination with the MVA (Mevalonic acid) pathway enzymes, 2.5 fold isoprene yield was enhanced, (Bentley et al., 2014). In another study Synechococcus elongatus PCC 7942 was engineered for the production of isoprene by over expressing isopentenyl pyrophosphate isomerase (idi) in combination with isoprene synthase which resulted $1.26 \mathrm{~g} / \mathrm{l}$ isoprene production (Gao et al, 2016).

\subsection{Limonene}

Limonene, a 10-carbon isoprenoid molecule is mainly synthesized in plants. Limonene is commonly found in the peel of citrus fruits and smells like orange. Limonene has been recognized as a substitute fuel for diesel and jet fuels (Tracy et al., 2009; Chucks et al., 2014). In cyanobacteria, isoprenoids are synthesized by MEP (methyl erythritol 4 phosphate) pathway. The end products of MEP pathway are IPP and DMAPP which acts as precursors of limonene and can be converted to limonene by limonene synthase enzyme. Although cyanobacteria do not possess limonene synthase gene, researchers utilize limonene synthase gene from the plants and transfer into cyanobacteria. In a research, limonene synthase gene from the plant Schizonepeta tenuifolia was introduced intoSynechocystis sp. PCC 6803 under the control of a strong promoter. They also cloned three genes that are involved in the synthesis of precursors of limonene, dimethyl allyl pyrophosphate (DMAPP) and isopentenyl pyrophosphate (IPP) via methyl erythritol 4 phosphate (MEP) pathway (Kiyota et al., 2014). In another studySynechococcuselongatus 7942 was genetically modified with limonene synthase gene from the spearmint (Mentha spicata) under the control of isopropyl $\beta$-D galactopyrenoside (IPTG) inducible promoter $\mathrm{P}_{\text {trc }}$ (Wang et al 2016). Mentha spicata and Citrus limon origin limonene synthase gene were transferred in cyanobacterial strain Synechocystis6803 to enhance the limonene production. Two-fold higher limonene was produced by limonene synthase from $M$. spicata compared to $C$. limon (Lin et al., 2017).

\section{$4.3 \alpha-\Phi \propto \rho \nu \varepsilon \sigma \varepsilon \nu \varepsilon$}

$\alpha$-Farnesene (3,7, 11-trimethyldodeca-1,3E,6E,10-tetraene) plays a role in plant defence and was found first in apple peel. It is one of the simplest acyclic sesquiterpenes. Naturally, it helps in pollination, seed dispersion, 
etc. and acts as a chemical signalling agent (Köllner et al., 2009; Pechous and Whitaker, 2004). Being less hygroscopic in nature and having high energy density (cetane numbers of 58) it forms the precursor for jet biofuel (Peralta and Keasling, 2010; Yang et al., 2016, Renninger and Mcphee, 2008). It has a cloud point of -78 degC compared with D2 diesel's cloud point of -3 degC. It also forms the precursor for solvents, polymers (Yoo et al., 2017), emollients, and vitamins. Amyris Biotechnologies, headquartered in Emeryville CA, a renewable products company engineered Saccharomyces cerevisiae to produce farnesene from sugarcane sucrose. Cyanobacteria have MEP pathway by which precursors of all sesquiterpenes are formed. Several efforts have been made to produce $\alpha$-farnesene through genetic modification and metabolic engineering such as Escherichia coli (0.38 mg/g of glycerol) (Wang et al., 2011), Saccharomyces cerevisiae (0.57 mg/g of glucose) (Tippmann et al., 2017) and Yarrowia lipolytica (6.5 mg/g of glucose and fructose) (Yang et al., 2016). The stated organisms are heterotrophic in nature and require a carbon source for their growth. Recently researchers have moved their focus to cyanobacteria, which can utilize carbon dioxide and light to produce farnesene. Anabaena sp. PCC 7129 (filamentous cyanobacteria) yielded $305.4 \mu \mathrm{g} / \mathrm{L}$ farnesene in 15 days (Halfmann et al., 2014). The strain started producing farnesene by directly incorporating plasmid having farnesene synthase gene (from Norway spruce). Similarly,Synechococcus elongatus PCC 7942 (naturally competent cyanobacteria) was engineered to express heterologous farnesene synthase gene (Lee et al., 2017). The production of $\alpha$-Farnesene from carbon dioxide was found to be $4.6 \pm 0.4 \mathrm{mg} / \mathrm{L}$ in 7 days.

\subsection{Alkanes}

Alkanes are one of the major constituents of petroleum. They include gasoline, diesel oil propane, lubricants and many more fuel molecules. Industrial scale refining of petroleum requires a high energy input and huge manpower and also many toxic by-products are generated which cause environmental pollution. Alternatively, alkane can be produced by cyanobacterial cell factories. There are mainly two alkane biosynthetic pathways have been identified in cyanobacteria till now. In one pathway fatty acyl-ACP is converted into fatty aldehydeby the enzyme fatty acyl ACP reductase (FAR). Fatty aldehyde is further converted into alkanes by aldehyde deformylating oxigenase (ADO). In second pathway mainly alkenes are synthesized via a polyketide synthase enzyme. Wang and coworkers constructed a series of Synechocystis PCC 6803 mutant strains by over expressing both acyl-acyl carrier protein reductase and aldehyde-deformylating oxygenase, the maximum yield was found to be $1.3 \%$ of DCW (Wang et al., 2013). Alkanes can also be produced by some cyanobacterial strains in salt stress conditions. When Anabaena sp. 7120 was grown in salt stress (nitrogen deficiency) condition, alkane yield was found $1200 \mu \mathrm{gg}^{-1} \mathrm{DCW}$ (Kageyama et al., 2015). Another research group overexpressed seven copies of FAR, ADO and a lipase in Nostoc punctiforme PCC 73102 which corresponded to $12.9 \%$ alkane of DCW (Peramuna et al, 2015).

\subsection{Squalene}

Squalene is a 30-carbon isoprenoid molecule, naturally synthesized by plants, animals and microorganisms via MEP and MVA pathways (Xu et al., 2016). Apart from many uses like cosmetics, food and medicine, squalene can be used as fuel instead of petroleum (Englund et al., 2014). Squalene is synthesized from farnesyl di-phosphate (FPP) in a two-step reaction catalyzed by squalene synthase. In first step, condensation reaction occurs between two FPP molecules and presqualene diphosphate (PSPP) is formed, which is further converted into squalene, utilizing a molecule of NADPH (Englund et al., 2014). Photosynthetic generation of squalene from $\mathrm{CO}_{2}$ is a great alternative solution of higher industrial production cost and minimization of pollutant emission. A research group predicted that Synechocystis PCC 6803 possess slr 2083 gene which encodes squalene hopene cyclase (shc) enzyme which catalyzes squalene conversion into hopene. Inactivation of slr 2083 gene resulted into $0.67 \mathrm{mg} \mathrm{L}^{-1}$ squalene, seventy time higher than wild strain (Englund et al., 2014). Squalene production has also been done in model cyanobacterium Synechococcus elongatus 7942 in which squalene synthase gene was joined to either a key enzyme FPP of the MEP pathway or the $\beta$-subunit of phycocyanin. Engineered strain resulted squalene production $11.98 \mathrm{mgL}^{-1}$ (Choi et. al., 2017). 


\subsection{Isobutanol}

Isobutanol, a branched-chain alcohol consisting of four carbon molecules, has great importance as gasoline additive for fuel purpose due to its higher energy value (Lu et al., 2012). It can be used as substitute (drop in fuel) for a variety of petroleum hydrocarbons without any modification of engine (Peralta et al., 2012). A research group introduced CoA (Co-enzyme A) dependent 1- butanol production pathway into Synechococcus elongatus PCC 7942. In this pathway, treponemadenticola- coA reductase (ter) works as proton donor and reduces crotonyl- coA to butyryl-coA. Trans-enoyl-coA activity was enhanced in the presence of poly histidine tag. $13.6 \mathrm{mg} / \mathrm{L} \mathrm{1-} \mathrm{butanol} \mathrm{was} \mathrm{produced} \mathrm{(Lan} \mathrm{et} \mathrm{al.,} \mathrm{2011).} \mathrm{In} \mathrm{another} \mathrm{study,} \mathrm{Synechocystis}$ PCC 6803 was engineered for the expression of two heterologous genes from the Ehrlich pathway, which can synthesize isobutanol in autotrophic and mixotrophic conditions. Isobutanol was separated from the production medium by oleyl alcohol as a solvent. $298 \mathrm{mg} / \mathrm{L}$ of isobutanol was produced under mixotrophic condition (Varman et al., 2013). The biological synthesis of isobutanol can be done by 2- keto acid pathway. Mainly branched chain amino acids are synthesized by this pathway.Escherichia coli (E. coli ) (Atsumi et al., 2009)Saccharomycescerevisiae (Yuan et al., 2017), and cyanobacteria (Atsumi et al., 2009, Miao et al., 2017, Miao et al., 2018) has been metabolically engineered with isobutanol biosynthesis pathway. In a study cyanobacterium Synechocystis PCC 6803 washeterologously expressed with an $\alpha$-ketoisovalerate decarboxylase (Kivd) gene fromLactococcus lactis (L. lactis ) which resulted in an isobutanol and 3-methyl1-butanol (3M1B) producing strain (Miao et al., 2018).

\subsection{Fatty acids}

Fatty acids are one of the prominent fuel molecules consisting of long alkyl chains, a great petroleum substitute for energy requirements (Pandey et al., 2019). Triacylglycerides (TAGs) are converted to fatty acid methyl esters (FAMEs) and fatty acid ethyl esters (FAEEs) by transesterification reaction. A prominent biological approach for biodiesel production is the transesterification of cyanobacterial fatty acids due to their capacity to capture and fix environmental $\mathrm{CO}_{2}$. Although cyanobacteria possess lipid biosynthesis pathway, but they do not accumulate neutral lipids in normal environmental conditions (Wada et al., 1990). In cyanobacteria lipid production in nutrient stress conditions has been reported by many researchers. In a study, supply of nitrogen and phosphorus (important nutrients) were limited to observe its effect on lipid productivity in selected cyanobacteria. Oscillatoria sp., Anabaena sp., Microcoleus sp., and Nostoc sp. varied in their ability to accumulate lipids which ranged from a lowest of $0.13 \%$ in Anabaena sp . to the maximum of $7.24 \%$ in Microcoleus sp . (Kumar et al., 2017). Apart from natural lipid synthesis and applying stress condition, the cyanobacterium can also be genetically modified for the enhanced lipid synthesis. Liu and co-workers genetically engineered synechocystis PCC6803 with codon optimized acyl-acyl carrier protein thioesterase gene. The fatty acid secretion yield was increased up to $197 \pm 14 \mathrm{mgL}^{-1}$ (Liu et al., 2011). Synechococcos elongatus PCC 7942 was engineered for the production of free fatty acids by knocking out acyl-ACP synthetase encoding gene and thioesterase encoding gene was over expressed for secretion of free fatty acids which resulted very low yield (Ruffing and Jones, 2012). A research group engineered Synechocystis PCC 6803 for enhanced fatty acid synthesis using a novel strategy. They targeted genes encoding acetyl-coA carboxylase (fatty acids synthesis), lipase A (phospholipid hydrolysis) and acyl-acyl carrier protein synthetase (recycling of free fatty acids). Maximum lipid production was observed up to $34.5 \% \mathrm{w} / \mathrm{DCW}$ corresponding $41.4 \mathrm{mg} / \mathrm{l} / \mathrm{d}$ in the strain which was engineered with acyl-acyl carrier protein synthetase encoding gene (Eungrasamee et al., 2019). In another study, rbc LXS and glpD genes of calvin- Benson- basham (CBB) and acyl-ACP synthetase encoding genes were engineered inSynechocystis PCC 6803. Modified strain was reported to produce 35.9\% DCW intracellular lipid and 9.6\% extracellular free fatty acids (Eungrasamee et al., 2020). 


\section{Concluding Remarks and Future Perspectives}

Harvesting solar energy by the process of photosynthesis is one of the nature's noteworthy accomplishments which can be utilized for creating sustainable and renewable energy sources. Cyanobacteria have emerged as suitable cell factories in recent years because of their limited nutritional requirements, phototrophic nature and simple genetic composition. Due to simplicity in genetic manipulation, it has attracted the attention of researchers for the photosynthetic production of a wide variety of carbon neutral fuels and other value-added chemicals from $\mathrm{CO}_{2}$. Use of synthetic biology tools has simplified metabolic engineering of cyanobacteria. Synthetic biology provides insights into toolboxes like promoters, ribosome binding sites, riboswitches, terminators and CRISPR/Cas tools for the efficient heterologous expression of gene of interest. Till now researchers have produced fuel molecules like isoprene, limonene, squalene, alkanes and butanol by cyanobacteria in good yield by engineering the biosynthetic pathway of metabolite of interest utilizing tools of synthetic biology. In forthcoming years there are chances of increasing the research of cyanobacterial biofuel production. Currently there is scope of designing scalable photo bioreactors and developing efficient and economic downstream processes.

\section{Acknowledgements}

Indrajeet and AR are grateful to the Ministry of Human Resource and Development (MHRD), India for financial aid. SK acknowledge the seed grant project provided by the IIT(BHU) Varanasi and research facility.

\section{Declaration}

This submitted work has not been published and is not under consideration for publication elsewhere, its publication is approved by all authors and tacitly or explicitly by the responsible authorities where the work was carried out, and if accepted, it will not be published elsewhere in the same form, in English or in any other language, including electronically without the written consent of the copyright holder.

\section{Ethical statement}

The authors declare no conflict of interest.

\section{Declaration of competing interests}

The authors declare that they have no known competing financial interests or personal relationships that could have appeared to influence the work reported in this paper.

\section{References}

Abramson, B. W., Kachel, B., Kramer, D. M., \& Ducat, D. C. (2016). Increased photochemical efficiency in cyanobacteria via an engineered sucrose sink. Plant and Cell Physiology , 57 (12), 2451-2460

Albers, S. C., \& Peebles, C. A. (2017). Evaluating Light-Induced Promoters for the Control of Heterologous Gene Expression in Synechocystis sp. PCC 6803. Biotechnology progress , 33 (1), 45-53.

Almeida, D. V., Martens, S. B. B., Lanes, C. F. C., \&Marins, L. F. (2017). Improved genetic transformation of Synechococcus elongatus PCC 7942 using linear DNA fragments in association with a DNase inhibitor. Biotechnology Research and Innovation , 1 (1), 123-128.

Andersson, C. R. (2000). Application of bioluminescence to the study of circadian rhythms in cyanobacteria. Methods Enzymol. , $305,527-542$.

Atsumi, S. Higashide, W., \& Liao, J. C. (2009). Direct photosynthetic recycling of carbon dioxide to isobutyraldehyde. Nature biotechnology , 27 (12)1177.

Atsumi, S., Wu, T. Y., Eckl, E. M., Hawkins, S. D., Buelter, T., \& Liao, J. C. (2010).Engineering the isobutanol biosynthetic pathway in Escherichia coli by comparison of three aldehyde reductase/alcohol dehydrogenase genes. Applied microbiology and biotechnology , 85 (3), 651-657. 
Barkley, S. J., Desai, S. B., \& Poulter, C. D. (2004). Type II isopentenyl diphosphate isomerase from Synechocystis sp. strain PCC 6803. Journal of bacteriology , 186 (23), 8156-8158.

Behle, A., Saake, P., Germann, A. T., Dienst, D., \&Axmann, I. M. (2020). Comparative dose-response analysis of inducible promoters in Cyanobacteria. ACS synthetic biology, 9 (4), 843-855.

Bentley, F. K., \&Melis, A. (2012). Diffusion-based process for carbon dioxide uptake and isoprene emission in gaseous/aqueous two-phase photobioreactors by photosynthetic microorganisms. Biotechnology and bioengineering , 109 (1), 100-109.

Bentley, F. K., Zurbriggen, A., \&Melis, A. (2014). Heterologous expression of the mevalonic acid pathway in cyanobacteria enhances endogenous carbon partitioning to isoprene. Molecular plant , 7 (1), 71-86.

Brosius J., Erfle M., and Storella J. (1984). Spacing of the -10 and -35 regions in the tac promoter. Journal of Biological Chemistry.260(6), 3539-3541.

Camsund, D., Heidorn, T., \& Lindblad, P. (2014). Design and analysis of LacI-repressed promoters and DNA-looping in a cyanobacterium. Journal of biological engineering , 8 (1), 4.

Chandrasekhar, K., Lee, Y. J., \& Lee, D. W. (2015). Biohydrogen production: strategies to improve process efficiency through microbial routes. International journal of molecular sciences , 16 (4), 8266-8293.

Chaves, J. E., \&Melis, A. (2018). Engineering isoprene synthesis in cyanobacteria. FEBS letters , 592 (12), 2059-2069.

Chemla, Y., Friedman, M., Heltberg, M., Bakhrat, A., Nagar, E., Schwarz, R., .. \& Alfonta, L. (2017). Expanding the genetic code of a photoautotrophic organism. Biochemistry , 56 (16), 2161-2165.

Chen, Y., Taton, A., Go, M., London, R. E., Pieper, L. M., Golden, S. S., \& Golden, J. W. (2016). Selfreplicating shuttle vectors based on pANS, a small endogenous plasmid of the unicellular cyanobacterium Synechococcus elongatus PCC 7942. Microbiology (United Kingdom) , 162 (12), 2029-2041.

Chi, X., Zhang, S., Sun, H., Qiao, C., Luan, G., \& Lu, X. (2019). Adopting a theophylline-responsive riboswitch for flexible regulation and understanding of glycogen metabolism in Synechococcus elongatus PCC7942. Frontiers in Microbiology, 10, 551.

Choi, S. Y., \& Woo, H. M. (2020). CRISPRi-dCas12a: A dCas12a-mediated CRISPR interference for repression of multiple genes and metabolic engineering in cyanobacteria. ACS synthetic biology , 9 (9), 2351-2361.

Choi, S. Y., Wang, J. Y., Kwak, H. S., Lee, S. M., Um, Y., Kim, Y., .. \& Woo, H. M. (2017). Improvement of squalene production from CO2 in Synechococcus elongatus PCC 7942 by metabolic engineering and scalable production in a photobioreactor. ACS Synthetic Biology , 6 (7), 1289-1295.

Choi, Y. N., Shin, Y. R., Park, J. M., \& Lee, J. W. (2021). Cell-Free Transcription-Coupled CRISPR/Cas12a Assay for Prototyping Cyanobacterial Promoters. ACS Synthetic Biology .

Chuck, C. J., \& Donnelly, J. (2014). The compatibility of potential bioderived fuels with Jet A-1 aviation kerosene. Applied Energy , 118 , 83-91.

Cohen, S. E., Erb, M. L., Selimkhanov, J., Dong, G., Hasty, J., Pogliano, J., \& Golden, S. S. (2014). Dynamic localization of the cyanobacterial circadian clock proteins. Current Biology , 24 (16), 1836-1844.

Desmarais, J. J., Flamholz, A. I., Blikstad, C., Dugan, E. J., Laughlin, T. G., Oltrogge, L. M., .. \& \& Savage, D. F. (2019). DABs are inorganic carbon pumps found throughout prokaryotic phyla. Nature microbiology , 4 (12), 2204-2215.

Diao, J., Song, X., Zhang, L., Cui, J., Chen, L., \& Zhang, W. (2020). Tailoring cyanobacteria as a new platform for highly efficient synthesis of astaxanthin. Metabolic Engineering , 61, 275-287. 
Domin, G., Findeiss, S., Wachsmuth, M., Will, S., Stadler, P. F., \&Morl, M. (2016). Applicability of a computational design approach for synthetic riboswitches. Nucleic acids research , 45 (7), 4108-4119.

Engler, C., Youles, M., Gruetzner, R., Ehnert, T. M., Werner, S., Jones, J. D., .. \&Marillonnet, S. (2014). A golden gate modular cloning toolbox for plants. ACS synthetic biology , 3 (11), 839-843.

Englund, E., Andersen-Ranberg, J., Miao, R., Hamberger, B., \& Lindberg, P. (2015). Metabolic engineering of Synechocystis sp. PCC 6803 for production of the plant diterpenoidmanoyl oxide. ACS synthetic biology , 4 (12), 1270-1278.

Englund, E., Liang, F., \& Lindberg, P. (2016). Evaluation of promoters and ribosome binding sites for biotechnological applications in the unicellular cyanobacterium Synechocystis sp. PCC 6803. Scientific reports , 6,36640 .

Englund, E., Pattanaik, B., Ubhayasekera, S. J. K., Stensjo, K., Bergquist, J., \& Lindberg, P. (2014). Production of squalene in Synechocystis sp. PCC 6803. PloS one, 9 (3), e90270.

Eungrasamee, K., Incharoensakdi, A., Lindblad, P., \&Jantaro, S. (2020). Synechocystis sp. PCC 6803 overexpressing genes involved in $\mathrm{CBB}$ cycle and free fatty acid cycling enhances the significant levels of intracellular lipids and secreted free fatty acids. Scientific reports , 10 (1), 1-13.

Eungrasamee, K., Miao, R., Incharoensakdi, A., Lindblad, P., \&Jantaro, S. (2019). Improved lipid production via fatty acid biosynthesis and free fatty acid recycling in engineered Synechocystis sp. PCC 6803. Biotechnology for biofuels, 12 (1), 8.

Fleming, K. E., \& O'Shea, E. K. (2018). An RpaA-dependent sigma factor cascade sets the timing of circadian transcriptional rhythms in Synechococcuselongatus. Cell reports , 25 (11), 2937-2945.

Flores, F. G. (2008). The cyanobacteria: molecular biology, genomics, and evolution . Horizon Scientific Press.

Formighieri, C., \& Melis, A. (2015). A phycocyanin* phellandrene synthase fusion enhances recombinant protein expression and $\beta$-phellandrene (monoterpene) hydrocarbons production in Synechocystis (cyanobacteria). Metabolic engineering, 32 , 116-124.

Gao, X., Gao, F., Liu, D., Zhang, H., Nie, X., \& Yang, C. (2016). Engineering the methylerythritol phosphate pathway in cyanobacteria for photosynthetic isoprene production from $\mathrm{CO}$ 2. Energy $\mathscr{E}$ environmental science , 9 (4), 1400-1411.

Griese, M., Lange, C., \&Soppa, J. (2011). Ploidy in cyanobacteria. FEMS microbiology letters , 323 (2), 124-131.

Halfmann, C., Gu, L., Gibbons, W., \& Zhou, R. (2014). Genetically engineering cyanobacteria to convert $\mathrm{CO} 2$, water, and light into the long-chain hydrocarbon farnesene. Applied microbiology and biotechnology , 98 (23), 9869-9877.

Heidorn, T., Camsund, D., Huang, H. H., Lindberg, P., Oliveira, P., Stensjö, K., \& Lindblad, P. (2011). Synthetic biology in cyanobacteria: engineering and analyzing novel functions. In Methods in enzymology (Vol. 497, pp. 539-579). Academic Press.

Helliwell, K. E., Lawrence, A. D., Holzer, A., Kudahl, U. J., Sasso, S., Kräutler, B., .. \& Smith, A. G. (2016). Cyanobacteria and eukaryotic algae use different chemical variants of vitamin B12. Current Biology , 26 (8), 999-1008.

Henkin, T. M. (2008). Riboswitch RNAs: using RNA to sense cellular metabolism. Genes 63 development, 22 (24), 3383-3390.

Higo, A., Isu, A., Fukaya, Y., Ehira, S., \& Hisabori, T. (2017). Application of CRISPR interference for metabolic engineering of the heterocyst-forming multicellular cyanobacterium Anabaena sp. PCC 7120. Plant 
and Cell Physiology , 59 (1), 119-127.

Huang, H. H., \& Lindblad, P. (2013). Wide-dynamic-range promoters engineered for cyanobacteria. Journal of biological engineering ,7 (1), 10.

Huang, H. H., Camsund, D., Lindblad, P., \&Heidorn, T. (2010). Design and characterization of molecular tools for a synthetic biology approach towards developing cyanobacterial biotechnology. Nucleic acids research, 38 (8), 2577-2593.

Ivleva, N. B., Bramlett, M. R., Lindahl, P. A., \& Golden, S. S. (2005). LdpA: a component of the circadian clock senses redox state of the cell. The EMBO journal , 24 (6), 1202-1210.

Jacobsen, J. H., \&Frigaard, N. U. (2014). Engineering of photosynthetic mannitol biosynthesis from CO2 in a cyanobacterium. Metabolic engineering , 21 , 60-70.

Jin, H., Wang, Y., Idoine, A., \&Bhaya, D. (2018). Construction of a shuttle vector using an endogenous plasmid from the cyanobacterium Synechocystis sp. PCC6803. Frontiers in microbiology , 9 , 1662.

Johnsborg, O., Eldholm, V., \&Håvarstein, L. S. (2007). Natural genetic transformation: prevalence, mechanisms and function. Research in microbiology , 158 (10), 767-778.

Kaczmarzyk, D., Cengic, I., Yao, L., \& Hudson, E. P. (2018). Diversion of the long-chain acyl-ACP pool in Synechocystis to fatty alcohols through CRISPRi repression of the essential phosphate acyltransferase PlsX. Metabolic engineering , 45, 59-66

Kageyama, H., Waditee-Sirisattha, R., Sirisattha, S., Tanaka, Y., Mahakhant, A., \&Takabe, T. (2015).Improved alkane production in nitrogen-fixing and halotolerant cyanobacteria via abiotic stresses and genetic manipulation of alkane synthetic genes. Current microbiology , 71 (1), 115-120.

Kaneko, T., Sato, S., Kotani, H., Tanaka, A., Asamizu, E., Nakamura, Y., .. \& \& Kimura, T. (1996). Sequence analysis of the genome of the unicellular cyanobacterium Synechocystis sp. strain PCC6803. II. Sequence determination of the entire genome and assignment of potential protein-coding regions. DNA research , 3 (3), 109-136.

Kelly, C. L., Taylor, G. M., Hitchcock, A., Torres-Mendez, A., \& Heap, J. T. (2018). A rhamnose-inducible system for precise and temporal control of gene expression in cyanobacteria. ACS synthetic biology , 7 (4), 1056-1066.

Kierzek, A. M., Zaim, J., \&Zielenkiewicz, P. (2001). The effect of transcription and translation initiation frequencies on the stochastic fluctuations in prokaryotic gene expression. Journal of Biological Chemistry , 276 (11), 8165-8172.

Kiyota, H., Okuda, Y., Ito, M., Hirai, M. Y., \&Ikeuchi, M. (2014). Engineering of cyanobacteria for the photosynthetic production of limonene from CO2. Journal of biotechnology , 185 , 1-7.

Knoot, C. J., Ungerer, J., Wangikar, P. P., \& Pakrasi, H. B. (2018). Cyanobacteria: promising biocatalysts for sustainable chemical production. Journal of Biological Chemistry , 293 (14), 5044-5052

Köllner, T. G., Gershenzon, J., \& Degenhardt, J. (2009). Molecular and biochemical evolution of maize terpene synthase 10, an enzyme of indirect defense. Phytochemistry , 70 (9), 1139-1145.

Kumar, G., Sivagurunathan, P., Pugazhendhi, A., Thi, N. B. D., Zhen, G., Chandrasekhar, K., \&Kadier, A. (2017). A comprehensive overview on light independent fermentative hydrogen production from wastewater feedstock and possible integrative options. Energy conversion and management , 141 , 390-402.

Kumar, R., Biswas, K., Singh, P. K., Singh, P. K., Elumalai, S., Shukla, P., \& Pabbi, S. (2017). Lipid production and molecular dynamics simulation for regulation of acc D gene in cyanobacteria under different $\mathrm{N}$ and $\mathrm{P}$ regimes. Biotechnology for biofuels , 10 (1), 1-14. 
Lan, E. I., \& Liao, J. C. (2011). Metabolic engineering of cyanobacteria for 1-butanol production from carbon dioxide. Metabolic engineering , 13 (4), 353-363.

Lasry Testa, R., Delpino, C., Estrada, V., \& Diaz, S. M. (2019). In silico strategies to couple production of bioethanol with growth in cyanobacteria. Biotechnology and bioengineering , 116 (8), 2061-2073.

Lee, H. J., Choi, J. I., \& Woo, H. M. (2021). Biocontainment of Engineered Synechococcus elongatus PCC 7942 for Photosynthetic Production of $\alpha$-Farnesene from CO2. Journal of Agricultural and Food Chemistry , 69 (2), 698-703.

Lee, H. J., Lee, J., Lee, S. M., Um, Y., Kim, Y., Sim, S. J., .. \& Woo, H. M. (2017). Direct conversion of CO2 to $\alpha$-farnesene using metabolically engineered Synechococcus elongatus PCC 7942. Journal of agricultural and food chemistry , 65 (48), 10424-10428.

Li, H., Shen, C. R., Huang, C. H., Sung, L. Y., Wu, M. Y., \& Hu, Y. C. (2016). CRISPR-Cas9 for the genome engineering of cyanobacteria and succinate production. Metabolic engineering , 38 , 293-302.

Lichtenthaler, H. K. (2000). Non-mevalonate isoprenoid biosynthesis: enzymes, genes and inhibitors.

Lin, P. C., Zhang, F., \& Pakrasi, H. B. (2020). Enhanced production of sucrose in the fast-growing cyanobacterium Synechococcus elongatus UTEX 2973. Scientific Reports, 10 (1), 1-8.

Lin, P. C., Zhang, F., \& Pakrasi, H. B. (2021). Enhanced limonene production in a fast-growing cyanobacterium through combinatorial metabolic engineering. Metabolic Engineering Communications , 12, e00164.

Lin, P. C., Saha, R., Zhang, F., \& Pakrasi, H. B. (2017). Metabolic engineering of the pentose phosphate pathway for enhanced limonene production in the cyanobacterium Synechocysti s sp. PCC 6803. Scientific reports, 7 (1), 1-10.

Lindberg, P., Park, S., \&Melis, A. (2010). Engineering a platform for photosynthetic isoprene production in cyanobacteria, using Synechocystis as the model organism. Metabolic engineering, 12 (1), 70-79.

Liu, D., \& Pakrasi, H. B. (2018). Exploring native genetic elements as plug-in tools for synthetic biology in the cyanobacterium Synechocystis sp. PCC 6803. Microbial cell factories , 17 (1), 48.

Liu, X., Sheng, J., \& Curtiss III, R. (2011).Fatty acid production in genetically modified cyanobacteria. Proceedings of the National Academy of Sciences , 108 (17), 6899-6904.

Lu, J., Brigham, C. J., Gai, C. S., \&Sinskey, A. J. (2012). Studies on the production of branched-chain alcohols in engineered Ralstoniaeutropha. Applied microbiology and biotechnology , 96 (1), 283-297

Lu, X. (2010). A perspective: photosynthetic production of fatty acid-based biofuels in genetically engineered cyanobacteria. Biotechnology advances , 28 (6), 742-746..

Lynch, S. A., \& Gallivan, J. P. (2008). A flow cytometry-based screen for synthetic riboswitches. Nucleic acids research, 37 (1), 184-192.

Ma, A. T., Schmidt, C. M., \& Golden, J. W. (2014). Regulation of gene expression in diverse cyanobacterial species by using theophylline-responsive riboswitches. Appl. Environ. Microbiol. , 80 (21), 6704-6713.

Ma, J., Campbell, A., \&Karlin, S. (2002). Correlations between Shine-Dalgarno sequences and gene features such as predicted expression levels and operon structures. Journal of bacteriology ,184 (20), 5733-5745.

Madsen, M. A., Hamilton, G., Herzyk, P., \&Amtmann, A. (2020). Environmental Regulation of PndbA600, an Auto-Inducible Promoter for Two-Stage Industrial Biotechnology in Cyanobacteria. Frontiers in bioengineering and biotechnology , 8 .

Markley, A. L., Begemann, M. B., Clarke, R. E., Gordon, G. C., \& Pfleger, B. F. (2014). Synthetic biology toolbox for controlling gene expression in the cyanobacterium Synechococcus sp. strain PCC 7002.ACS synthetic biology, 4 (5), 595-603. 
Melis, A. (2012). Photosynthesis-to-fuels: from sunlight to hydrogen, isoprene, and botryococcene production. Energy \& Environmental Science, 5 (2), 5531-5539.

Miao, R., Liu, X., Englund, E., Lindberg, P., \& Lindblad, P. (2017). Isobutanol production in Synechocystis PCC 6803 using heterologous and endogenous alcohol dehydrogenases. Metabolic engineering communications , $5,45-53$.

Na, D., \& Lee, D. (2010). RBS Designer: software for designing synthetic ribosome binding sites that yields a desired level of protein expression. Bioinformatics , 26 (20), 2633-2634.

Nagarajan, A., Winter, R., Eaton-Rye, J., \&Burnap, R. (2011). A synthetic DNA and fusion PCR approach to the ectopic expression of high levels of the D1 protein of photosystem II in Synechocystis sp. PCC 6803. Journal of Photochemistry and Photobiology B: Biology , 104 (1-2), 212-219.

Nakahira, Y., Ogawa, A., Asano, H., Oyama, T., \&Tozawa, Y. (2013). Theophylline-dependent riboswitch as a novel genetic tool for strict regulation of protein expression in cyanobacterium Synechococcus elongatus PCC 7942. Plant and Cell Physiology, 54 (10), 1724-1735.

Ng, A. H., Berla, B. M., \&Pakrasi, H. B. (2015). Fine-tuning of photoautotrophic protein production by combining promoters and neutral sites in the cyanobacterium Synechocystis sp. strain PCC 6803. Appl. Environ. Microbiol. , 81 (19), 6857-6863.

Ohbayashi, R., Akai, H., Yoshikawa, H., Hess, W. R., \& Watanabe, S. (2016). A tightly inducible riboswitch system in Synechocystis sp. PCC 6803. The Journal of general and applied microbiology . 62, 154-159.

Oliver, J. W., Machado, I. M., Yoneda, H., \&Atsumi, S. (2014). Combinatorial optimization of cyanobacterial 2, 3-butanediol production.Metabolic engineering, 22, 76-82.

Pade, N., Erdmann, S., Enke, H., Dethloff, F., Dühring, U., Georg, J., . . \& Hagemann, M. (2016). Insights into isoprene production using the cyanobacterium Synechocystis sp. PCC 6803. Biotechnology for biofuels , 9 (1), 1-16.

Pandey, A., Srivastava, S., \& Kumar, S. (2019). Isolation, screening and comprehensive characterization of candidate microalgae for biofuel feedstock production and dairy effluent treatment: a sustainable approach. Bioresource technology , 293 , 121998.

Pandey, A., Srivastava, S., \& Kumar, S. (2020). Development and cost-benefit analysis of a novel process for biofuel production from microalgae using pre-treated high-strength fresh cheese whey wastewater. Environmental Science and Pollution Research, 27 (19), 23963-23980.

Parikh, M. R., Greene, D. N., Woods, K. K., \& Matsumura, I. (2006). Directed evolution of RuBisCO hypermorphs through genetic selection in engineered E. coli. Protein Engineering Design and Selection, 19 (3), 113-119.

Pattanaik, B., Englund, E., Nolte, N., \& Lindberg, P. (2020). Introduction of a green algal squalene synthase enhances squalene accumulation in a strain of Synechocystis sp. PCC 6803. Metabolic engineering communications , 10 , e00125.

Pechous, S. W., \& Whitaker, B. D. (2004). Cloning and functional expression of an (E, E)- $\alpha$-farnesene synthase cDNA from peel tissue of apple fruit. Planta, 219 (1), 84-94.

Peralta-Yahya, P. P., \&Keasling, J. D. (2010). Advanced biofuel production in microbes. Biotechnology journal , 5 (2), 147-162.

Peralta-Yahya, P. P., Zhang, F., Del Cardayre, S. B., \&Keasling, J. D. (2012). Microbial engineering for the production of advanced biofuels. Nature , 488 (7411), 320-328.

Peramuna, A., Morton, R., \&Summers, M. L. (2015). Enhancing alkane production in cyanobacterial lipid droplets: a model platform for industrially relevant compound production. Life , 5 (2), 1111-1126. 
Pérez, A. A., Liu, Z., Rodionov, D. A., Li, Z., \& Bryant, D. A. (2016). Complementation of cobalamin auxotrophy in Synechococcus sp. strain PCC 7002 and validation of a putative cobalamin riboswitch in vivo. Journal of bacteriology , 198 (19), 2743-2752.

Reeve, B., Hargest, T., Gilbert, C., \& Ellis, T. (2014). Predicting translation initiation rates for designing synthetic biology.Frontiers in bioengineering and biotechnology , $2,1$.

Renninger, N. S., \&Mcphee, D. J. (2008). U.S. Patent No. 7,399,323 . Washington, DC: U.S. Patent and Trademark Office.

Ruffing, A. M. (2011). Engineered cyanobacteria: teaching an old bug newtricks. Bioengineered bugs , 2 (3), 136-149.

Ruffing, A. M., \& Jones, H. D. (2012). Physiological effects of free fatty acid production in genetically engineered Synechococcus elongatus PCC 7942. Biotechnology and bioengineering , 109 (9), 2190-2199.

Ruffing, A. M., Jensen, T. J., \& Strickland, L. M. (2016). Genetic tools for advancement of Synechococcus sp. PCC 7002 as a cyanobacterial chassis. Microbial cell factories , 15 (1), 190.

Salis, H. M. (2011). The ribosome binding site calculator. In Methods in enzymology (Vol. 498, pp. 19-42). Academic Press.

Salis, H. M., Mirsky, E. A., \& Voigt, C. A. (2009). Automated design of synthetic ribosome binding sites to control protein expression. Nature biotechnology , 27 (10), 946.

Sebesta, J., \& Peebles, C. A. (2020). Improving heterologous protein expression in Synechocystis sp. PCC 6803 for alpha-bisabolene production. Metabolic engineering communications , 10 , e00117.

Sengupta, A., Pritam, P., Jaiswal, D., Bandyopadhyay, A., Pakrasi, H. B., \& Wangikar, P. P. (2020). Photosynthetic co-production of succinate and ethylene in a fast-growing cyanobacterium, Synechococcus elongatus PCC 11801. Metabolites, 10 (6), 250.

Seo, S. W., Yang, J. S., Kim, I., Yang, J., Min, B. E., Kim, S., \& Jung, G. Y. (2013). Predictive design of mRNA translation initiation region to control prokaryotic translation efficiency. Metabolic engineering , 15 , 67-74.

Shono, C., Ariyanti, D., Abe, K., Sakai, Y., Sakamoto, I., Tsukakoshi, K., .. \& I Ikebukuro, K. (2021). A green light-regulated T7 RNA polymerase gene expression system for cyanobacteria. Marine Biotechnology , 23 (1), 31-38.

Singh, P., Kumar, N., Jethva, M., Yadav, S., Kumari, P., Thakur, A., \& Kushwaha, H. R. (2018). Riboswitch regulation in cyanobacteria is independent of their habitat adaptations. Physiology and molecular biology of plants , 24 (2), 315-324.

Song, K., Tan, X., Liang, Y., \& Lu, X. (2016). The potential of Synechococcus elongatus UTEX 2973 for sugar feedstock production. Applied microbiology and biotechnology , 100 (18), 7865-7875.

Stucken, K., Koch, R., \& Dagan, T. (2013). Cyanobacterial defense mechanisms against foreign DNA transfer and their impact on genetic engineering. Biological research , 46 (4), 373-382.

Sun, E. I., Leyn, S. A., Kazanov, M. D., Saier, M. H., Novichkov, P. S., \&Rodionov, D. A. (2013). Comparative genomics of metabolic capacities of regulons controlled by cis-regulatory RNA motifs in bacteria. $B M C$ genomics , 14 (1), 597.

Taton, A., Unglaub, F., Wright, N. E., Zeng, W. Y., Paz-Yepes, J., Brahamsha, B., ... \& Golden, J. W. (2014). Broad-host-range vector system for synthetic biology and biotechnology in cyanobacteria. Nucleic acids research , 42 (17), e136-e136. 
Thiel, K., Mulaku, E., Dandapani, H., Nagy, C., Aro, E. M., \& Kallio, P. (2018). Translation efficiency of heterologous proteins is significantly affected by the genetic context of RBS sequences in engineered cyanobacterium Synechocystis sp. PCC 6803. Microbial cell factories , 17 (1), 34.

Tippmann, S., Ferreira, R., Siewers, V., Nielsen, J., \& Chen, Y. (2017). Effects of acetoacetyl-CoA synthase expression on production of farnesene in Saccharomyces cerevisiae. Journal of industrial microbiology $\mathcal{E}^{3}$ biotechnology , 44 (6), 911-922.

Topp, S., Reynoso, C. M., Seeliger, J. C., Goldlust, I. S., Desai, S. K., Murat, D., .. \& \& Scott, J. R. (2010). Synthetic riboswitches that induce gene expression in diverse bacterial species. Appl. Environ. Microbiol., 76 (23), 7881-7884.

Tracy, N. I., Chen, D., Crunkleton, D. W., \& Price, G. L. (2009). Hydrogenated monoterpenes as diesel fuel additives. Fuel , 88 (11), 2238-2240.

Ungerer, J., \& Pakrasi, H. B. (2016). Cpf1 is a versatile tool for CRISPR genome editing across diverse species of cyanobacteria. Scientific reports , 6 , 39681.

Varman, A. M., Xiao, Y., Pakrasi, H. B., \& Tang, Y. J. (2013). Metabolic engineering of Synechocystis sp. strain PCC 6803 for isobutanol production. Appl. Environ. Microbiol., 79 (3), 908-914.

Vasudevan, R., Gale, G. A., Schiavon, A. A., Puzorjov, A., Malin, J., Gillespie, M. D., .. \& Lea-Smith, D. J. (2019). CyanoGate: A modular cloning suite for engineering cyanobacteria based on the plant MoClo syntax. Plant physiology, 180 (1), 39-55.

Vioque, A. (2007). Transformation of cyanobacteria. In Transgenic microalgae as green cell factories (pp. 12-22). Springer, New York, NY.

Wada, H., \& Murata, N. (1990). Temperature-induced changes in the fatty acid composition of the cyanobacterium, Synechocystis PCC6803. Plant Physiology, 92 (4), 1062-1069.

Wang, B., Eckert, C., Maness, P. C., \& Yu, J. (2017). A genetic toolbox for modulating the expression of heterologous genes in the cyanobacterium Synechocystis sp. PCC 6803. ACS synthetic biology ,7 (1), 276-286.

Wang, C., Yoon, S. H., Jang, H. J., Chung, Y. R., Kim, J. Y., Choi, E. S., \& Kim, S. W. (2011). Metabolic engineering of Escherichia coli for $\alpha$-farnesene production. Metabolic engineering , 13 (6), 648-655.

Wang, W., Liu, X., \& Lu, X. (2013). Engineering cyanobacteria to improve photosynthetic production of alka (e) nes. Biotechnology for biofuels , 6 (1), 69.

Wang, X., Liu, W., Xin, C., Zheng, Y., Cheng, Y., Sun, S., \& Yuan, J. S. (2016). Enhanced limonene production in cyanobacteria reveals photosynthesis limitations. Proceedings of the National Academy of Sciences, 113 (50), 14225-14230.

Watanabe, S., Ohbayashi, R., Kanesaki, Y., Saito, N., Chibazakura, T., Soga, T., \& Yoshikawa, H. (2015). Intensive DNA replication and metabolism during the lag phase in cyanobacteria. PLoS One, 10 (9), e0136800.

Wegelius, A., Li, X., Turco, F., \&Stensjö, K. (2018). Design and characterization of a synthetic minimal promoter for heterocyst-specific expression in filamentous cyanobacteria. PloS one, 13 (9), e0203898.

Wendt, K. E., Ungerer, J., Cobb, R. E., Zhao, H., \&Pakrasi, H. B. (2016). CRISPR/Cas9 mediated targeted mutagenesis of the fast growing cyanobacterium Synechococcus elongatus UTEX 2973. Microbial cell factories , 15 (1), 115.

Werner, A., Oliver, K., Miller, A. D., Sebesta, J., \& Peebles, C. A. (2018). Discovery and characterization of Synechocystis sp. PCC 6803 light-entrained promoters in diurnal light: dark cycles. Algal research , 30, 121-127. 
Woo, H. M. (2017). Solar-to-chemical and solar-to-fuel production from CO2 by metabolically engineered microorganisms. Current opinion in biotechnology , 45, 1-7.

Xia, P. F., Ling, H., Foo, J. L., \& Chang, M. W. (2019). Synthetic biology toolkits for metabolic engineering of cyanobacteria. Biotechnology journal, 14 (6), 1800496.

Xu, W., Ma, X., \& Wang, Y. (2016). Production of squalene by microbes: an update. World Journal of Microbiology and Biotechnology, 32 (12), 195

Xu, Y., Alvey, R. M., Byrne, P. O., Graham, J. E., Shen, G., \& Bryant, D. A. (2011). Expression of genes in cyanobacteria: adaptation of endogenous plasmids as platforms for high-level gene expression in Synechococcus sp. PCC 7002. In Photosynthesis research protocols (pp. 273-293). Humana Press, Totowa, NJ.

Yang, X., Nambou, K., Wei, L., \& Hua, Q. (2016). Heterologous production of $\alpha$-farnesene in metabolically engineered strains of Yarrowia lipolytica. Bioresource technology , 216 , 1040-1048.

Yao, L., Cengic, I., Anfelt, J., \& Hudson, E. P. (2015). Multiple gene repression in cyanobacteria using CRISPRi. ACS synthetic biology, 5 (3), 207-212.

Yoo, T.; Chao, H.; Henning, S. Farnesene-Based Polymers and Liquid Optically Clear Adhesive Compositions Incorporating the Same.WO Patent 2017003573 A1, Jan 5, 2017.

Yu, J., Liberton, M., Cliften, P. F., Head, R. D., Jacobs, J. M., Smith, R. D., \& Pakrasi, H. B. (2015). Synechococcus elongatus UTEX 2973, a fast growing cyanobacterial chassis for biosynthesis using light and CO 2. Scientific reports, 5,8132 .

Yuan, J., Chen, X., Mishra, P., \& Ching, C. B. (2017).Metabolically engineered Saccharomyces cerevisiae for enhanced isoamyl alcohol production. Applied microbiology and biotechnology , 101 (1), 465-474.

Zahra, Z., Choo, D. H., Lee, H., \& Parveen, A. (2020). Cyanobacteria: review of current potentials and applications. Environments, 7 (2), 13.

Zerulla, K., Ludt, K., \&Soppa, J. (2016). The ploidy level of Synechocystis sp. PCC 6803 is highly variable and is influenced by growth phase and by chemical and physical external parameters. Microbiology , 162 (5), 730-739.

Zhang, Y., \&Gladyshev, V. N. (2008). Molybdoproteomes and evolution of molybdenum utilization. Journal of molecular biology , 379 (4), 881-899.

Zhou, J., Yang, F., Zhang, F., Meng, H., Zhang, Y., \& Li, Y. (2021). Impairing photorespiration increases photosynthetic conversion of CO 2 to isoprene in engineered cyanobacteria. Bioresources and Bioprocessing , 8 (1), 1-13.

Zhou, J., Zhang, H., Meng, H., Zhu, Y., Bao, G., Zhang, Y., .. \& \& Ma, Y. (2014). Discovery of a superstrong promoter enables efficient production of heterologous proteins in cyanobacteria. Scientific reports , 4 , 4500 .

\section{List of figures}

Figure 1 : Replacement of neutral site with gene of interest (GOI): Target gene gets inserted in the place of neutral sites by homologous recombination process.

Figure 2 : Biosynthetic pathway of different fuel molecules in cyanobacteria; Methyl erythritol 4-phosphate (MEP) pathway is used for various terpenoid synthesis in cyanobacteria (Prokaryotes) whereas mevalonic acid pathway (MVA) is used in eukaryotes and archaebacteria for terpenoid synthesis. Abbreviations used: G3P- Glyceraldehyde 3-phosphate; RuBP- Ribulose bisphosphate; 3 PGA- 3 phosphoglycerate; BPG- bisphosphoglycerate; 2PGA- phosphoglycerate; PEP- phosphoenol pyruvate; DXS- Deoxy xylulose 5-phosphate 
synthase; DXP- Deoxy Xylulose 5-phosphate; DXR- DXP reductoisomerase; MEP- Methyl erythritol phosphate; IspD- CDP-ME synthase; CDP-ME- diphosphocytidylyl methylerythritol; IspE- CDP-ME kinase; CDP-MEP- diphosphocytidylyl methylerythritol phosphate; IspF- ME-cPP synthase; ME-cPP- methyl erythritol-2,4- cyclodiphosphate; IspG- HMBPP synthase; HMBPP- Hydroxymethylbutenyl diphosphate; IspH- HMBPP reductase; DMAPP- Dimethyl allyl diphosphate; Ipi- IPP isomerase; IPP- Isopentenyl diphosphate; ISPS- Isoprene synthase; GPP- Geranyl bisphosphate; FPP- Farnesyl diphosphate; GGPP- Geranyl geranyl diphosphate; PSPP- Presqualene diphosphate; PDH- Pyruvate dehydrogenase.

\section{List of tables}

Table 1: Cyanobacterial host organisms used for synthetic biology approach

Table 2: List of native and foreign promoters used in cyanobacteria

Table 3: List of commercially available replicative plasmid

Table 4: Integrative plasmids available commercially

Table 5: DNA transfer strategies followed for different strains of cyanobacteria

Table 6: Production of fuel molecules by genetically engineered cyanobacteria

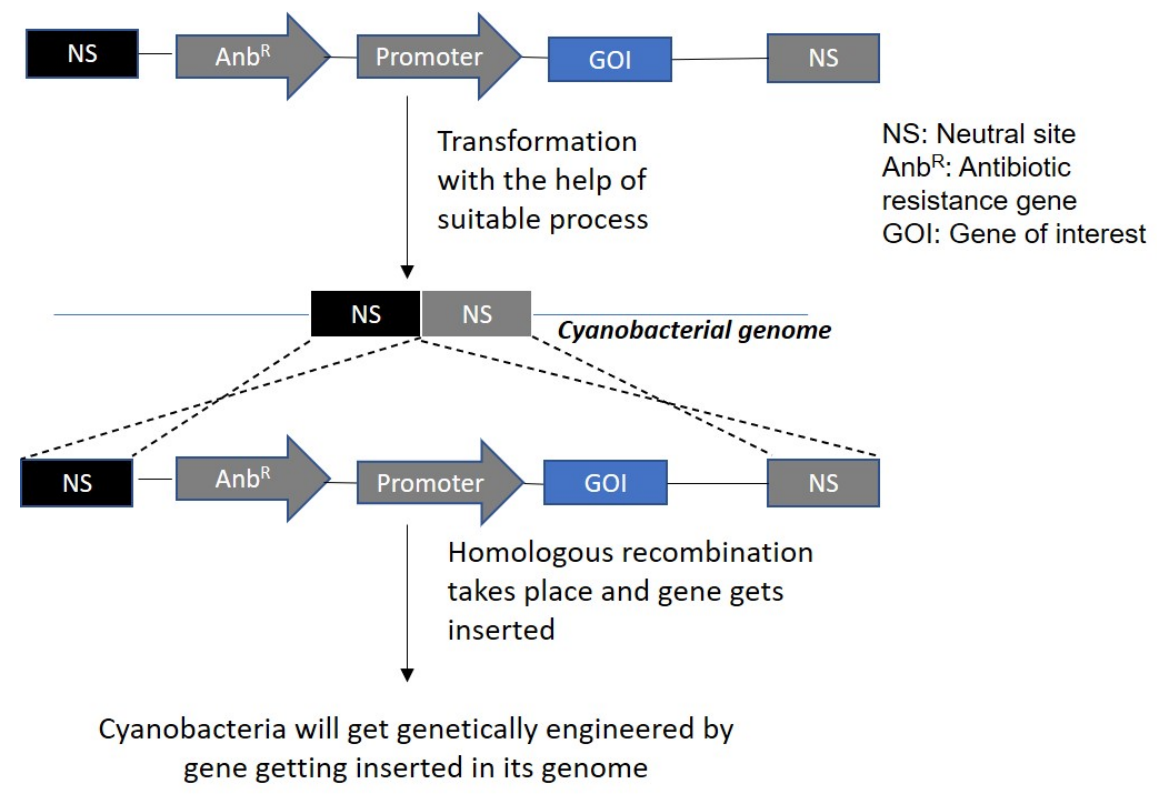




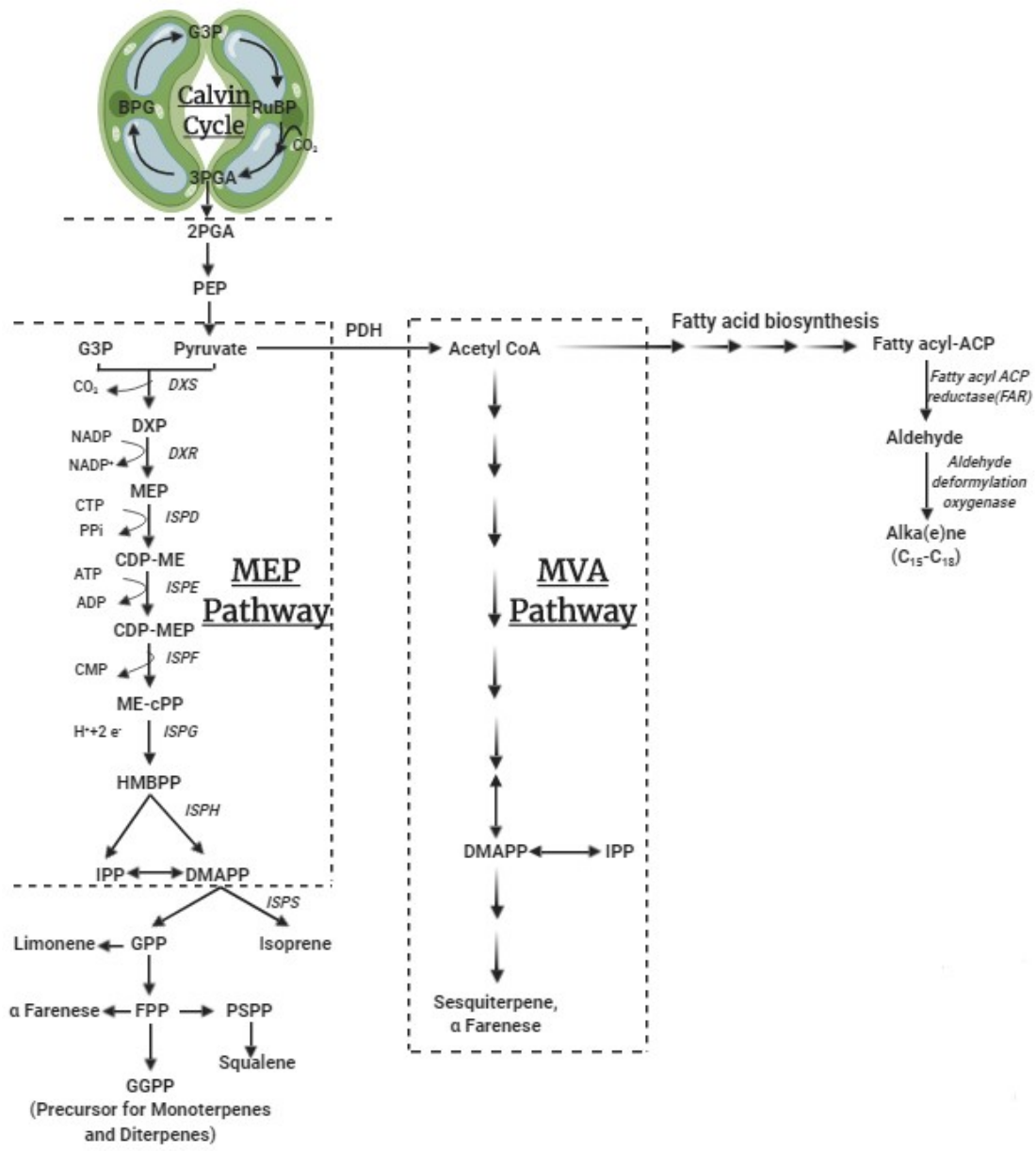

\section{Hosted file}

Table updated.docx available at https://authorea.com/users/427348/articles/531525-approachesin-the-photosynthetic-production-of-sustainable-fuels-by-cyanobacteria-using-tools-ofsynthetic-biology 